\title{
Genotype-phenotype correlations of new causative APC gene mutations in patients with familial adenomatous polyposis
}

\author{
David J Bunyan, Janet Shea-Simonds, Anne C Reck, Derek Finnis, Diana M Eccles
}

\begin{abstract}
Nine new causative mutations and seven previously characterised mutations of the APC gene of patients with familial adenomatous polyposis (FAP) were analysed for any genotype-phenotype correlations. The only clear genotype-phenotype correlation found was between the position of the mutation site and the presence or absence of congenital hypertrophy of the retinal pigment epithelium (CHRPE). A more distal mutation site was associated with an earlier age of onset of symptoms and a larger number of colonic polyps, but a notable amount of intrafamilial variation was observed.
\end{abstract}

(f Med Genet 1995;32:728-731)

Familial adenomatous polyposis (FAP) is an autosomal dominant disorder that accounts for approximately $1 \%$ of all colorectal cancers. Adenomatous polyps develop throughout the colon, usually between the second and fourth decades of life. These polyps inevitably progress to cancer, often by the mid 30s. Upper gastrointestinal polyps are also seen in some affected people and the risk for death from upper gastrointestinal malignancy is about $5 \%$, but this usually occurs two to three decades later than colorectal malignancy. ${ }^{1}$ Other extraintestinal manifestations include epidermoid cysts, osteomas, desmoid tumours (Gardner's syndrome), and congenital hypertrophy of the retinal pigment epithelium (CHRPE). Colonoscopic screening for at risk people and a total colectomy when polyps develop is the preferred management.

Linkage to chromosome $5 \mathrm{q} 21$ was reported in 1987 and the APC gene, DP2.5, was cloned in $1991 .^{2-4}$ This tumour suppressor gene consists of 15 exons with a combined open reading frame of $8535 \mathrm{bp}$. Over $50 \%$ of all characterised chain terminating mutations so far identified are clustered in the $5^{\prime}$ end of exon 15, but there are only two common mutations, the $5 \mathrm{bp}$ deletion at codon 1061 ( $5 \%$ of all mutations) and the 5 bp deletion at codon 1309 (10-15\% of all mutations).
In 1993, an FAP register was established in Wessex as a two year pilot project with regional funding. Following a systematic screen of the APC gene of 30 unrelated people with FAP from this register, we report nine new causative mutations plus seven previously characterised mutations. In order to study genotype-phenotype effects and any intrafamilial variation in expression, the position of the mutation site in the proband of each pedigree, and in any other available affected family members, was correlated to three phenotypic features: CHRPE status, age at diagnosis of polyps, and number of polyps.

\section{Materials and methods}

PATIENTS

All patients tested were from the Wessex Polyposis Register. All available patients were examined by the same ophthalmologist using indirect ophthalmoscopy. Data concerning polyp number and age at diagnosis were retrieved from hospital notes. Molecular analysis was carried out on DNA extracted from circulating peripheral blood leucocytes.

\section{HETERODUPLEX ANALYSIS}

Genomic DNA (100 ng) was amplified using the relevant primers and conditions listed by Groden et al. ${ }^{3}$ The PCR products were heated to $95^{\circ} \mathrm{C}$ for three minutes then cooled to $37^{\circ} \mathrm{C}$ over a period of 30 minutes to form heteroduplexes before running $10 \mu \mathrm{l}$ of sample on a $24 \mathrm{~cm}$ Hydrolink gel (AT Biochem). Heteroduplex bands were visualised by ethidium bromide staining.

\section{SEQUENCING OF MUTATIONS}

PCR of the relevant region was performed using a biotin tagged forward primer (Oswel DNA services). A total of $100 \mu \mathrm{l}$ of the PCR product was run on $1 \%$ NuSieve (FMC Bioproducts) low melting point agarose gel, the PCR band was excised from the gel, and the biotinylated template strand for sequencing was isolated using Dynabeads (Dynal UK). Sequencing was carried out using a Sequenase Version 2.0 T7 
The APC gene mutations in 25 people from 16 separate FAP families. Where possible, the CHRPE status, age when polyps first seen, and the number of polyps is given for each affected family member

\begin{tabular}{|c|c|c|c|c|c|c|c|}
\hline Patient & Mutation & Effect & Exon & Codon & CHRPE status & Age polyps first seen & No of polyps \\
\hline W32 & - AATA & Frameshift & $4^{*}$ & 168 & -ve & 31 (FS) & $100 \mathrm{~s}$ \\
\hline W13.1 & $\mathrm{CAG} \rightarrow \mathrm{TAG}$ & Stop & 7 & 278 & -ve & 29 (FS) & $100 \mathrm{~s}$ \\
\hline W13.2 & $\mathrm{CAG} \rightarrow \mathrm{TAG}$ & Stop & 7 & 278 & & 51 (FS) & $100 \mathrm{~s}$ \\
\hline W33.1 & $-\mathrm{CT}$ & Frameshift & 9* & 366 & & 45 (FS) & $40+$ \\
\hline W33.2 & $-\mathrm{CT}$ & Frameshift & 9* & 366 & & 33 (FS) & $10 \mathrm{~s}$ \\
\hline W33.3 & - CT & Frameshift & $9^{*}$ & 366 & & 43 (FS) & 80 \\
\hline W33.4 & $-\mathrm{CT}$ & Frameshift & $9 *$ & 366 & $-\mathrm{ve}$ & 43 (FS) & $80+$ \\
\hline W19 & CTA $\rightarrow$ CTATA & Frameshift & $15 \mathrm{~A}^{*}$ & 656 & $\begin{array}{l}\text { +ve } \\
\text { + }\end{array}$ & 42 (FS) & $>1000$ \\
\hline W26.1 & TGT $\rightarrow$ T & Frameshift & $15 \mathrm{~A}^{*}$ & 661 & & 18 & $100-200$ \\
\hline W26.2 & $\mathrm{TGT} \rightarrow \mathrm{T}$ & Frameshift & $15 A^{*}$ & 661 & & 22 (FS) & Unknown \\
\hline W27 & $\mathrm{TGG} \rightarrow \mathrm{TGA}$ & Stop & $15 A^{*}$ & 699 & $+\mathrm{ve}$ & 15 (FS) & $>100$ \\
\hline W28 & $-\mathrm{A}$ & Frameshift & $15 \mathrm{~B}^{*}$ & 769 & +ve & 28 (FS) & $>1000$ \\
\hline W29.1 & $\mathrm{TAC} \rightarrow \mathrm{TAA}$ & Stop & $15 \mathrm{C}$ & 935 & $+\mathrm{ve}$ & 53 (FS) & $100 \mathrm{~s}$ \\
\hline W29.2 & $\mathrm{TAC} \rightarrow \mathrm{TAA}$ & Stop & $15 \mathrm{C}$ & 935 & & 29 & $100 \mathrm{~s}$ \\
\hline W29.3 & $\mathrm{TAC} \rightarrow \mathrm{TAA}$ & Stop & $15 \mathrm{C}$ & 935 & & 21 & Unknown \\
\hline $\mathrm{W} 21$ & - AAAAC & Frameshift & $15 \mathrm{E}$ & 1061 & $+\mathrm{ve}$ & $37(\mathrm{FS})$ & $100 \mathrm{~s}$ \\
\hline W38 & - AAAAC & Frameshift & $15 \mathrm{E}$ & 1061 & $+\mathrm{ve}$ & 25 & $>250$ \\
\hline W24 & AATCAA $\rightarrow$ AA & Frameshift & $15 \mathrm{E}$ & 1122 & & 23 & $100 \mathrm{~s}$ \\
\hline W42 & TTATAGTTTA $\rightarrow$ TTA & Frameshift & $15 \mathrm{~F}$ & 1178 & & 22 (FS) & Unknown \\
\hline W6 & $\mathrm{A} \rightarrow \mathrm{AA}$ & Frameshift & $15 \mathrm{~F}^{*}$ & 1187 & $+\mathrm{ve}$ & 26 (FS) & $>100 t$ \\
\hline W31 & $\mathrm{A} \rightarrow \mathrm{AA}$ & Frameshift & $15 \mathrm{~F}^{*}$ & 1193 & +ve & 28 & $>1000$ \\
\hline W20.1 & $\mathrm{GGA} \rightarrow \mathrm{TGA}$ & Stop & $15 \mathrm{G}$ & 1309 & & 17 (FS) & Unknownt \\
\hline $\mathrm{W} 20.2$ & $\mathrm{GGA} \rightarrow \mathrm{TGA}$ & Stop & $15 \mathrm{G}$ & 1309 & +ve & 15 (FS) & 1000 st \\
\hline W20.3 & GGA $\rightarrow$ TGA & Stop & $15 \mathrm{G}$ & 1309 & & 15 (FS) & 100st \\
\hline W41 & $\mathrm{T} \rightarrow \mathrm{TT}$ & Frameshift & $15 \mathrm{I}^{*}$ & 1557 & & 16 (FS) & $100 s \neq$ \\
\hline
\end{tabular}

(FS) Polyps discovered in the patient's colon during the first bowel screen.

* Previously uncharacterised mutation. † Patient also has Gardner’s syndrome. $¥$ Patient’s dead mother also had desmoid disease.

DNA Polymerase kit (United States Biochemical), labelling with ${ }^{35} \mathrm{~S}-\alpha \mathrm{CTP}$. Sequencing products were separated on a $6 \%$ polyacrylamide/urea denaturing gel and visualised by autoradiography or on a Fuji phosphoimager.

\section{Results}

Constitutional APC mutations were identified using a PCR based heteroduplex analysis method. Abnormal heteroduplex bands were subsequently analysed by direct sequencing. The results are listed in the table along with the relevant clinical details. The nine new causative mutations consist of eight frameshifts and one stop codon, all but two of which are in the mutation cluster region (MCR) at the $5^{\prime}$ end of exon 15 . The other seven causative mutations found have previously been characterised by other groups carrying out similar studies. ${ }^{5-8}$

People with mutations $5^{\prime}$ to exon 10 all had a negative CHRPE status and fewer than 1000 colonic polyps (although exact polyp counts were not recorded on most patients except where there were fewer than 100). The average age at diagnosis of polyps in this subset of people was 39.3 years $(n=7, \operatorname{SD} 8.3$ years). In contrast, all those with mutations $3^{\prime}$ to exon 9 who were examined by indirect ophthalmoscopy had a CHRPE positive phenotype. Each had hundreds or thousands of colonic polyps, and the average age at diagnosis of polyps was $25 \cdot 1$ years $(n=18$, SD 10.2 years).

\section{Discussion}

The recent cloning of the APC gene has led to the identification of well over 100 different mutations worldwide in the last three years. Thus, our discovery of nine new mutations is not surprising. Seven of these new mutations cluster in the $5^{\prime}$ end of exon 15 as expected from previous reviews of published mutations, with two of the patients reported here $5.9 \%$ of all unrelated patients on the Wessex Polyposis Register) having the common 5 bp deletion at codon 1061 , a figure in agreement with the $5 \%$ value previously quoted. ${ }^{910}$

Previous studies of genotype-phenotype correlations of APC mutations have shown a correlation between the position of the mutation site and one or more phenotypic features. The most commonly reported correlation is between the CHRPE status of patients and the site of the mutation, patients with a mutation in exons 1-9 being CHRPE negative while mutations $3^{\prime}$ to exon 9 are associated with a CHRPE positive phenotype. ${ }^{811-14}$ All 12 of the patients with causative mutations who were examined in our study support this previously reported observation. The new mutations in exons 4 and 9 and the previously characterised exon 7 mutation result in a CHRPE negative phenotype while all the exon 15 mutations result in a CHRPE positive phenotype.

Past investigations into the correlation between the mutation site and disease severity have shown an association between the size of the truncated protein product and the number of colonic polyps with larger mutant proteins leading to a more severe phenotype, although significant interfamilial and intrafamilial variation has been reported in patients with an identical mutation. ${ }^{121-18}$ An explanation for larger mutant proteins leading to a more severe phenotype can be found from studies of the binding effects of truncated APC protein molecules. A larger mutant protein is more prone to dimerisation with a wild type protein than a more proximally truncated APC protein. Such dimerisation renders the wild type protein effectively inactive, thus reducing cellular levels of normal protein activity. ${ }^{19-21}$ The data from our patients cannot support or refute this association owing to the small sample number and the difficulty of obtaining precise polyp counts retrospectively. However, the overall picture is consistent with this observation, and 
in families where accurate clinical information was available the expected pattern was followed. The 2 bp deletion in exon 9 seen in family W33 was associated with a low number of polyps in all four affected family members, whereas two of the exon 15 mutations (families W28 and W31) resulted in a manifestation of over 1000 polyps. For most families the clinical count of "hundreds of polyps" did not allow classification into high or low severity categories. Another problem when relating the numbers of polyps to the mutation site is that some patients, for example, the three affected members of family W20, were diagnosed at an early age and all had their colons removed. Had resection not taken place early, the number of polyps may have increased from hundreds to thousands, so these figures are not necessarily reflective of the severity of the phenotype. However, the detection of multiple polyps in these patients at such an early age is indicative of a more severe phenotype. Patient W6 and the three affected members of family W20 also suffer from the extracolonic manifestations described in classical Gardner's syndrome, while the dead mother of patient W41 had clinical evidence of desmoid disease; thus, other clinical factors may be of interest in genotype-phenotype correlations.

The third factor from our data to be related to the mutation site is the age at which polyps were first observed. Previously, a larger truncated protein product was reported to lead to an earlier age of onset, though quite a range of intrafamilial and interfamilial variation has been seen. ${ }^{171822-24}$ Such variation no doubt stems from the way in which tumour development is thought to occur. Although FAP patients have a constitutional mutation on one chromosome, the "two hit" theory describes the need for a second mutation to occur within the normal APC gene before a cell starts to proliferate. ${ }^{925}$ The timing of this second mutation will be subject to a wide range of external factors, such as natural carcinogens and diet, so variation in age of onset between people with the same mutation must be expected. In our studies, the age at which polyps were first observed was significantly higher (using Student's $t$ test, $\mathrm{p}<0.005$ ) in patients with a mutation $5^{\prime}$ to exon 10 (39.3 years) as compared to $25 \cdot 1$ years for patients with an exon 15 mutation. The age used in these calculations is the age at which the polyps were first seen during screening, but in many cases this was during the first ever bowel screen so polyps may well have developed many years before the examination. For these people, the age at which polyps were first seen may be considered inaccurate when attempting to relate these figures to the age of onset of symptoms. It can be counter-argued, however, that the reason these patients were not examined until a later age was because of the lack of symptoms, or later diagnosis in the closest affected relative (index case). The correlation may therefore still be valid. Considerable intrafamilial variation was seen, especially in families W13 and W29, so although an early age of onset ( $<20$ years) may be solely associated with an exon 15 mutation in our study, a later age of onset (such as in patients W19, W29.1, and W21) is not necessarily indicative of a more proximal mutation site.

The lack of reliable clinical information (in particular accurate polyp counting) hampers this type of study, as does inconsistent screening policies among surgeons. The establishment of regional registers for FAP will facilitate a more uniform approach to screening and follow up, allowing the collection of specific clinical data. With such data, clear conclusions may be drawn about genotype-phenotype correlations, which in turn will help to identify potential mutation sites. Of all the phenotypic manifestations, the CHRPE status of a person provides the most accurate and reliable evidence for the possible mutation site, though a severe phenotype with an early onset and thousands of polyps would be highly suggestive of a mutation in exon 15 . With this in mind, the gathering of as many clinical details as possible before screening of the APC gene should allow a more rapid genetic confirmation of suspected FAP in future patients.

This work was funded by a grant from the Wessex Regional Health Authority Development and Evaluation Committee.

1 Nugent KP, Spigelman AD, Phillips RKS. Life expectancy after colectomy and ileorectal anastomosis for familial adenomatous polyposis. Dis Colon Rectum 1993;36:105962.

2 Bodmer WF, Bailey CJ, Bodmer J, et al. Localisation of the gene for familial adenomatous polyposis on chromosome 5. Nature 1987;328:614-9.

3 Groden J, Thliveris A, Samowitz W, et al. Identification and characterisation of the familial adenomatous polyposis coli gene. Cell 1992;66:589-600.

4 Kinzler KW, Nilbert MC, Su L, et al. Identification of FAP locus genes from chromosome 5q21. Science 1991;253: $661-4$.

5 Fodde R, van der Luijt R, Wijnen J, et al. Eight novel inactivating germ line mutations at the APC gene identified by denaturing gel electrophoresis. Genomics 1992;13: by denatur

6 Miyoshi $\dot{Y}$, Nagase $\mathrm{H}$, Ando $\mathrm{H}$, et al. Somatic mutations of the APC gene in colorectal tumours: mutation cluster the APC gene in colorectal tumours: mutation cluster
region in the APC gene. Hum Mol Genet 1992;1:229-33.

7 Groden J, Gelbert L, Thliveris A, et al. Mutational analysis of patients with familial adenomatous polyposis: identical inactivating mutations in unrelated individuals. $\mathrm{Am} \mathcal{F} \mathrm{Hum}$ Genet 1993;52:263-72.

8 Wallis YL, Macdonald F, Hulten M, et al. Genotype-phenotype correlation between position of constitutional APC gene mutation and CHRPE expression in familial adenomatous polyposis. Hum Genet 1994;94:543-8.

9 Nagase H, Nakamura Y. Mutations of the APC (adenomatous polyposis coli) gene. Hum Mutat 1993;2:42534.

10 Mandl M, Paffenholz R, Friedl W, Caspari R, Sengteller M, Propping P. Frequency of common and novel inactivating polyposis. Hum Mol Genet 1994;3:181-4.

11 olschwang S, Tiret A, Laurent-Puig P, Muleris M, Parc R, Thomas G. Restriction of ocular fundus lesions to a specific subgroup of APC mutations in adenomatous specific subgroup of APC mutations in ader

12 Paul P, Letteboer T, Gelbert L, Groden J, White R, Coppes $M J$. Identical APC exon 15 mutations result in a variable phenotype in familial adenomatous polyposis. Hum $\mathrm{Mol}$ Genet 1993;2:25-31.

13 Wallis Y, Macdonald F, Morton D, et al. Detection of germline mutations in the APC gene in FAP families. $\mathcal{f}$ Med Genet 1993;30:333.

14 Caspari R, Friedl W, Mandl M, Moslein G, Kadmon M, Knapp M. Familial adenomatous polyposis: mutation at codon 1309 and early onset of colon cancer. Lancet 1994; 343:629-32.

15 Nagase H, Miyoshi Y, Horii A, et al. Correlation between the location of germ-line mutations in the APC gene and the number of colorectal polyps in familial adenomatous the number of colorectal polyps in familial ade

16 polyposis patients. Cancer Res 1992;52:4055-7. gene: an attenuated form of familial polyposis. Cell 1993; 75:951-7.

17 Gayther SA, Wells D, SenGupta SB, et al. Regionally clustered APC mutations are associated with a severe phenotype and occur at a high frequency in new mutation phenotype and occur at a high frequency in new mutation 3:53-6. 
18 Giardiello FM, Krush AJ, Petersen GM, et al. Phenotypic variability of familial adenomatous polyposis in 11 unrelated families with identical APC gene mutation. Gastroenterology 1994:106:1542-7.

19 Joslyn G, Richardson DS, White R, Alber T. Dimer formation by an N-terminal coiled coil in the APC protein. Proc Natl Acad Sci USA 1993;90:11109-13.

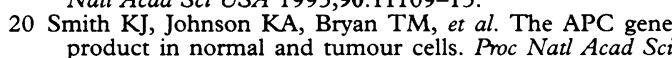

product in normal and tumour cells. Proc Natl Acad Sci
USA 1993;90:2846-50. Kinzler KW. Association between wild type and mutant APC gene products. Cancer Res 1993;53:2728-31.

22 Presciuttini S, Varesco L, Sala P, et al. Age of onset in familial adenomatous polyposis: heterogeneity within families and among APC mutations. Ann Hum Genet 1994;58:331-42.

23 Smith-Ravin J, Pack K, Hodgson S, Tay SKS, Phillips R Bodmer W. APC mutation associated with late onset of familial adenomatous polyposis. 7 Med Genet 1994;31: 888-90.

24 Varesco L, Gismondi V, Presciuttini S, et al. Mutation in a splice-donor site of the APC gene in a family with polyposis and late age of colonic cancer death. Hum Genet 1994;

25 Miyaki $M$, Konishi $M$, Kikuchi-Yanoshita $R$, et al. Coexistence of somatic and germline mutations of APC gene in desmoid tumours from patients with familia adenomatous polyposis. Cancer Res 1993;53:5079-82. 